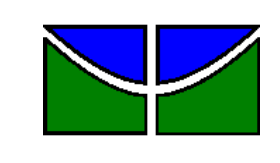

\begin{abstract}
UNIVERSIDADE DE BRASÍLIA
Faculdade de Educação - UAB/UnB/ MEC/SECAD

Curso de Especialização em Educação na Diversidade e Cidadania, com Ênfase em EJA
\end{abstract}

MICHELÂNGELO HEBERVAL BEZERRA LIMA

\begin{abstract}
A IMPORTÂNCIA DA FAMÍLIA PARA A AÇÃO COLETIVA CIDADÃ DOS ESTUDANTES DE EDUCAÇÃO DE JOVENS E ADULTOS DO CENTRO DE ENSINO MÉDIO 03 DE CEILÂNDIA - DF
\end{abstract}

BRASÍLIA, DF 
UNIVERSIDADE DE BRASÍLIA

Faculdade de Educação - UAB/UnB/ MEC/SECAD

Curso de Especialização em Educação na Diversidade e Cidadania, com Ênfase em EJA

\title{
A IMPORTÂNCIA DA FAMÍLIA PARA A AÇÃO COLETIVA CIDADÃ DOS ESTUDANTES DE EDUCAÇÃO DE JOVENS E ADULTOS DO CENTRO DE ENSINO MÉDIO 03 DE CEILÂNDIA - DF
}

\author{
MICHELÂNGELO HEBERVAL BEZERRA LIMA \\ PROFESSOR(A) ORIENTADOR(A): MARIA LUIZA PEREIRA ANGELIM \\ TUTOR(A) ORIENTADOR(A): MARIA DO SOCORRO DA SILVA LINHARES
}

PROJETO DE INTERVENÇÃO LOCAL

BRASÍLIA, DF Junho/2010 
UNIVERSIDADE DE BRASÍLIA

Faculdade de Educação - UAB/UnB/ MEC/SECAD

Curso de Especialização em Educação na Diversidade e Cidadania, com

Ênfase em EJA

MICHELÂNGELO HEBERVAL BEZERRA LIMA

\section{A IMPORTÂNCIA DA FAMÍLIA PARA A AÇÃO COLETIVA CIDADÃ DOS ESTUDANTES DE EDUCAÇÃO DE JOVENS E ADULTOS DO CENTRO DE ENSINO MÉDIO 03 DE CEILÂNDIA - DF}

Trabalho de conclusão do Curso de Especialização em Educação na Diversidade e Cidadania, com Ênfase em EJA, como parte dos requisitos necessários para obtenção do grau de Especialista na Educação de Jovens e Adultos 


\section{RESUMO}

Este Projeto de Intervenção intitulado A importância da Família para a Ação Coletiva Cidadã dos Estudantes de Educação de Jovens e Adultos do Centro de Ensino Médio 03 de Ceilândia-Df, é conseqüência, de minha atuação como professor e educador da Secretaria de Educação do DF, onde por meio da convivência diária com os alunos da Educaçao de Jovens e Adultos, da condição destes como sujeitos de EJA e trabalhadores, da minha atuação como membro do Fórum de Educação de Jovens Adultos - DF (Fórum EJA DF) e no Projeto Cine Popular, do Centro de Educação Paulo Freire de Ceilãndia (CEPAFRE), tive a oportunidade de perceber que a organização social da comunidade local pode ser construída por meio da problematização e intervenção na realidade por meio dos eventos pedagógicos da escola, quando estes se combinam com as ações dos movimentos sociais e da sociedade civil organizada. A comunidade local é constituída também pela comunidade escolar que, por sua vez, é formada por uma parcela significativa dos alunos e suas famílias, que são o núcleo básico desta organização.

Palavras-chave: EJA, Problematização, Intervenção, Sujeitos de EJA e Trabalhadores, Construção Coletiva. 


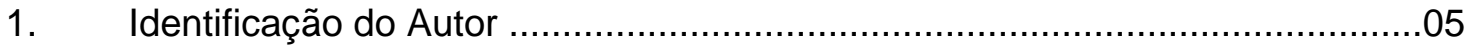

2. Dados de Identificação do Projeto ….................................................................

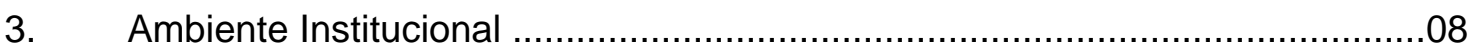

4. Justificativa e Caracterização do Problema .....................................................21

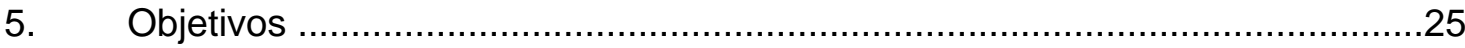

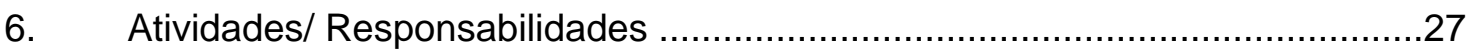

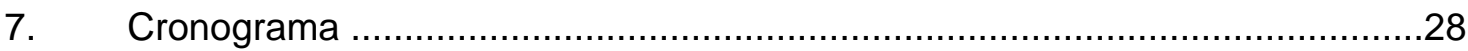

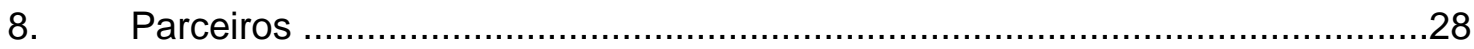

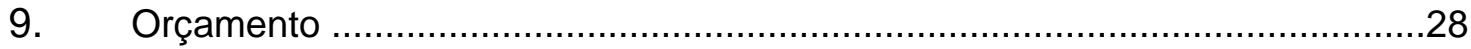

10. Acompanhamento e Avaliação ....................................................29

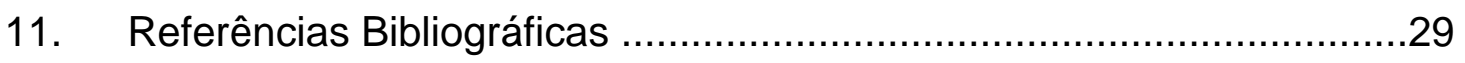




\section{Identificação do Autor}

1.1. NOME: Michelângelo Heberval Bezerra Lima

1.2. TURMA: C

1.3. ENDEREÇO POSTAL: QNO 11 CONJUNTO L CASA 13 - CEILÂNDIA - DF - CEP 72.255-112

1.4. TELEFONE FIXO: (61)33741394 TELEFONE CELULAR: (61)99655839 


\section{Dados de identificação do Projeto}

2.1. TíTULO: A Importância da Família para a Ação Coletiva Cidadã dos Estudantes de Educação de Jovens e Adultos - EJA do Centro de Ensino Médio 03 de Ceilândia - DF (CEM 03).

2.2. ÁREA DE ABRANGÊNCIA: a abrangência deste Projeto de Intervenção será voltada ao Centro de Ensino Médio 03 de Ceilândia - DF (CEM 03) e aos seus alunos de Educação de Jovens e Adultos. As figuras 1 e 2 mostram, respectivamente, o mapa do Distrito Federal com as Regiões Administrativas e uma fotografia aérea do Centro de Ensino Médio 03 na Região Administrativa de Ceilândia.

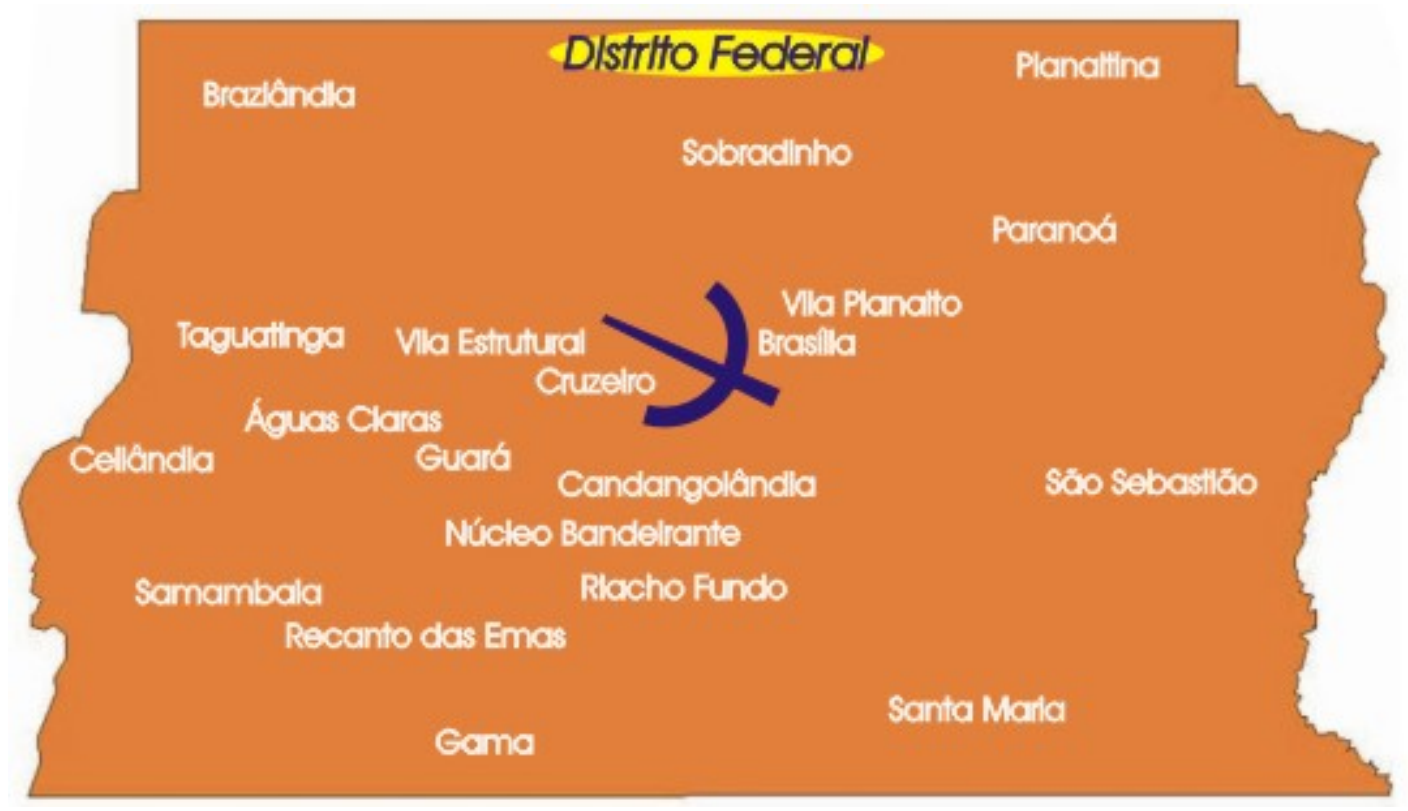

Figura 1: mapa obtido no Portal dos Fóruns de EJA no link: http://www.forumeja.org.br/df/cidades. Acesso em: 24/06/2010. 


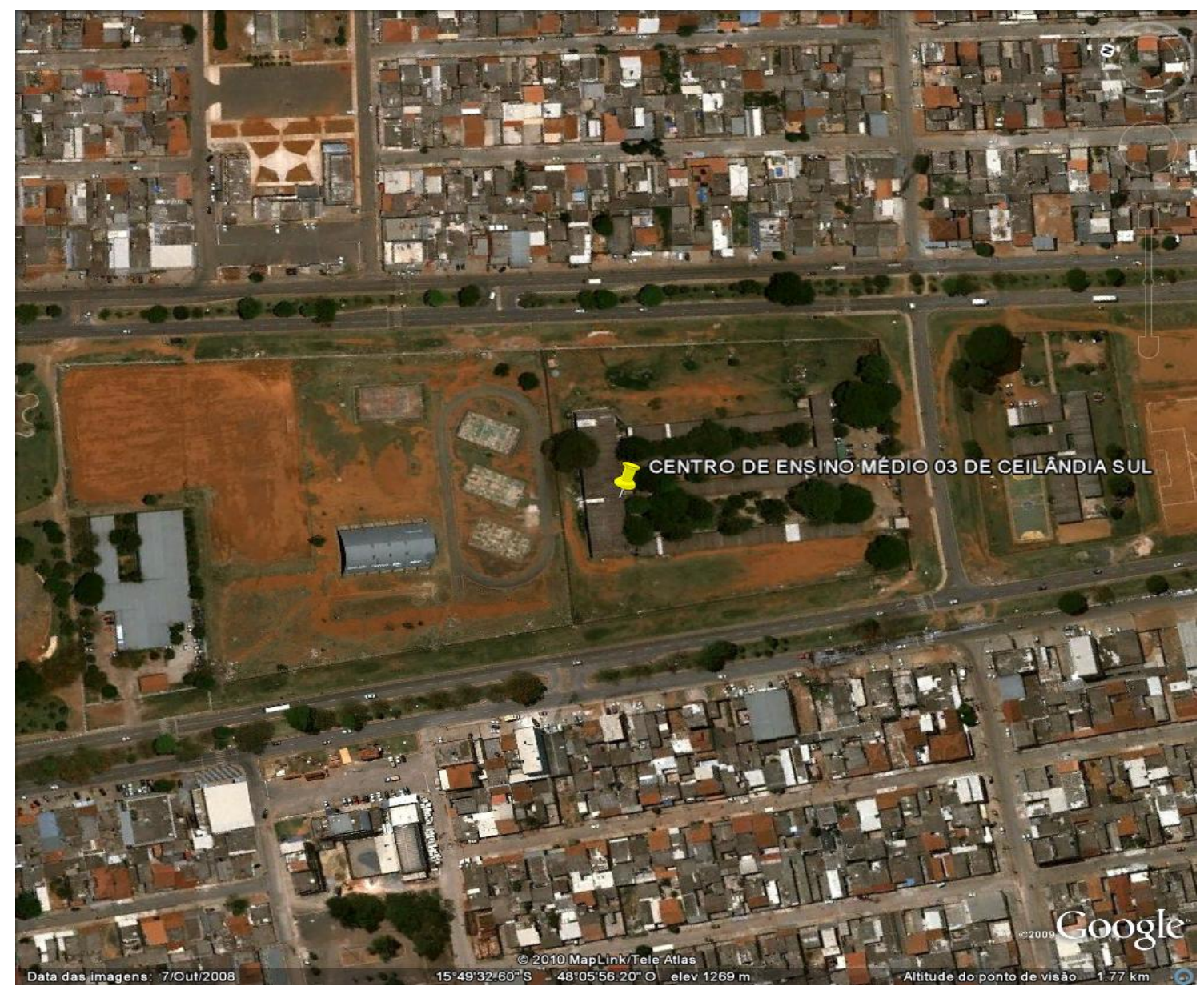

Figura 2: fotografia aérea obtida a partir do Google Earth no link http://maps.google.com/maps?\|=-15.820116,48.096478\&z=15\&t=h\&hl=pt-BR . Acesso em: 01/06/2010.

\subsection{Caracterização da Instituição}

Centro de Ensino Médio 03 de Ceilândia - DF (CEM 03)

Endereço: QNM 13 Área Especial S/N - Ceilândia - DF - CEP 72215-130

Instância institucional de decisão: Conselho Escolar. 


\subsection{Características do Público Alvo}

O público alvo do Centro de Ensino Médio 03 é constituído de alunos do ensino médio no período matutino e de alunos da EJA nos turnos vespertino e noturno, sendo que no vespertino funcionam os três segmentos da EJA e no noturno apenas o terceiro segmento. No vespertino a faixa etária vai dos 15 anos e mais, com uma mistura de adultos e idosos com jovens adolescentes. No noturno a maioria dos alunos são adultos e trabalhadores havendo alguns idosos. Um grande problema para os alunos do noturno é a segurança, agravada pela falta de iluminação nas imediações da escola e pela precariedade dos meios de transportes no horário da saída.

Os alunos são provenientes nos três turnos, mas principalmente na EJA, de todas as regiões da Ceilândia e até de outras regiões administrativas do DF e de municípios do entorno, como Águas Lindas de Goiás.

\subsection{Período de Execução:}

Início: segundo semestre letivo de 2010;

Término: ação permanente, a cada semestre letivo.

\section{Ambiente Institucional}

O Centro de Ensino Médio 03 de Ceilândia foi inaugurado em 12 de novembro de 1971, tendo suas atividades iniciadas nesta mesma data, com o nome Centro de Ensino de $1^{\circ} \mathrm{Grau}$

Atendia a alunos da $5^{\mathrm{a}}$ a $8^{\mathrm{a}}$ séries que eram oriundos principalmente das Escolas Classe, localizadas na Ceilândia Sul, fundadas na mesma época. Assim, os alunos cursavam o Jardim de Infância até a $4^{\mathrm{a}}$ série primária e em seguida eram encaminhados a estes Centros de Ensino para cursarem de $5^{\mathrm{a}}$ a $8^{\mathrm{a}}$ séries, encerrando assim $01^{\circ} \mathrm{grau}$, à época.

Como se tratava de um público alvo com idade a partir de 11 anos, a escola foi criada num espaço bem amplo onde se podia, entre outras coisas, aproveitar muito a prática desportiva, com quadras cobertas/descobertas, pista de atletismo, banco de areia para saltos à distância, entre outros.

Espaços abertos internos com canteiros e viveiro entre blocos de salas, salas de aula especiais equipadas com bancadas e pias, davam a esta escola a característica de ser grande para os que estavam saindo das Escolas Classe e com uma bela área verde. As figuras 3, 4 e 5 mostram o espaço físico do CEM 03. 


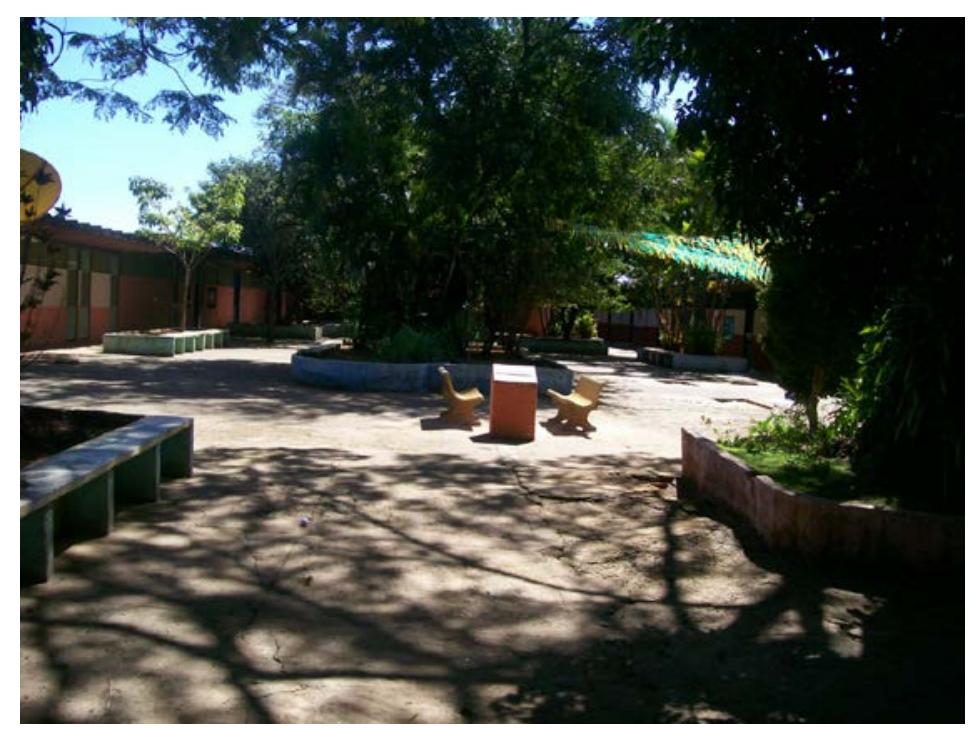

Figura 3: Área verde entre o Bloco A e D.

Em 11 de fevereiro de 1977, a Resolução no 95 - CD transformou a escola em Centro Interescolar $\mathrm{n}^{\circ} 01$ de Ceilândia, que foi posteriormente vinculado ao Complexo Escolar B de Ceilândia, que era mais conhecido popularmente como "Centro 01. A partir, daquele ano a modalidade de ensino foi ampliada e atingiu o $2^{\circ}$ grau. Em 17 de outubro do mesmo ano recebeu a denominação de Centro Educacional 03 de Ceilândia. E em 2000 o nome foi novamente alterado para Centro de Ensino Médio 03 de Ceilândia, quando a escola passou a ser especializada em Ensino Médio e Educação de Jovens e Adultos, permanecendo assim está denominação até o presente ano de 2010.

A estrutura física da escola foi adaptada para atender aos alunos com Deficiência Física, de acordo com as normas da própria Secretaria de Educação do Distrito Federal, com a construção de rampas de acesso aos corredores (figuras 4 e 5), piso rebaixado nas entradas das salas de aula, mobiliário diferenciado para atender alunos que necessitam de mesa individual (adquiridos perante a Regional de Ensino de Ceilândia), banheiros com barras, quadros brancos a pincel e quadro a giz nas salas de aula. 


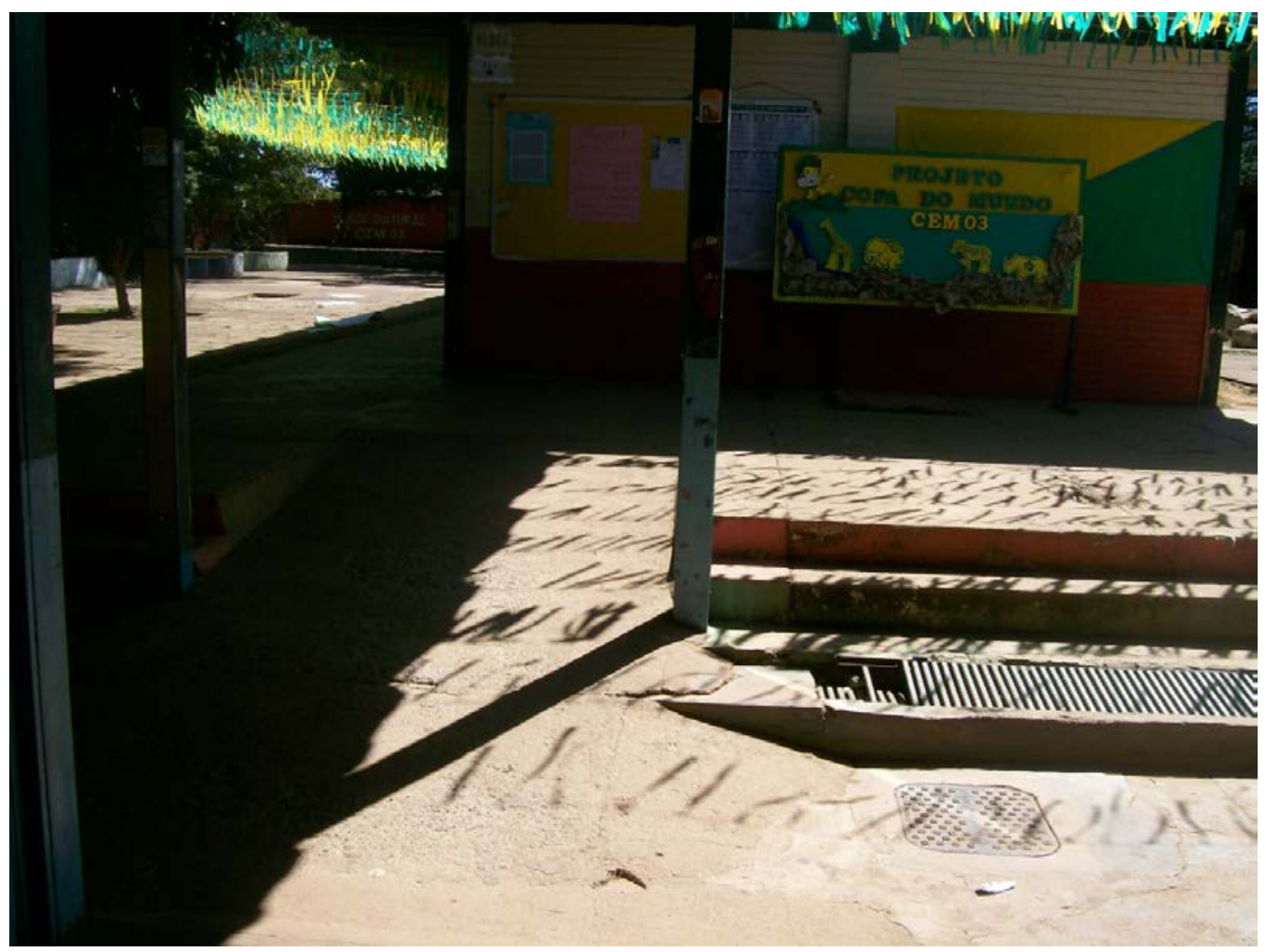

Figura 4: rampa de acesso ao bloco A, junho 2010.

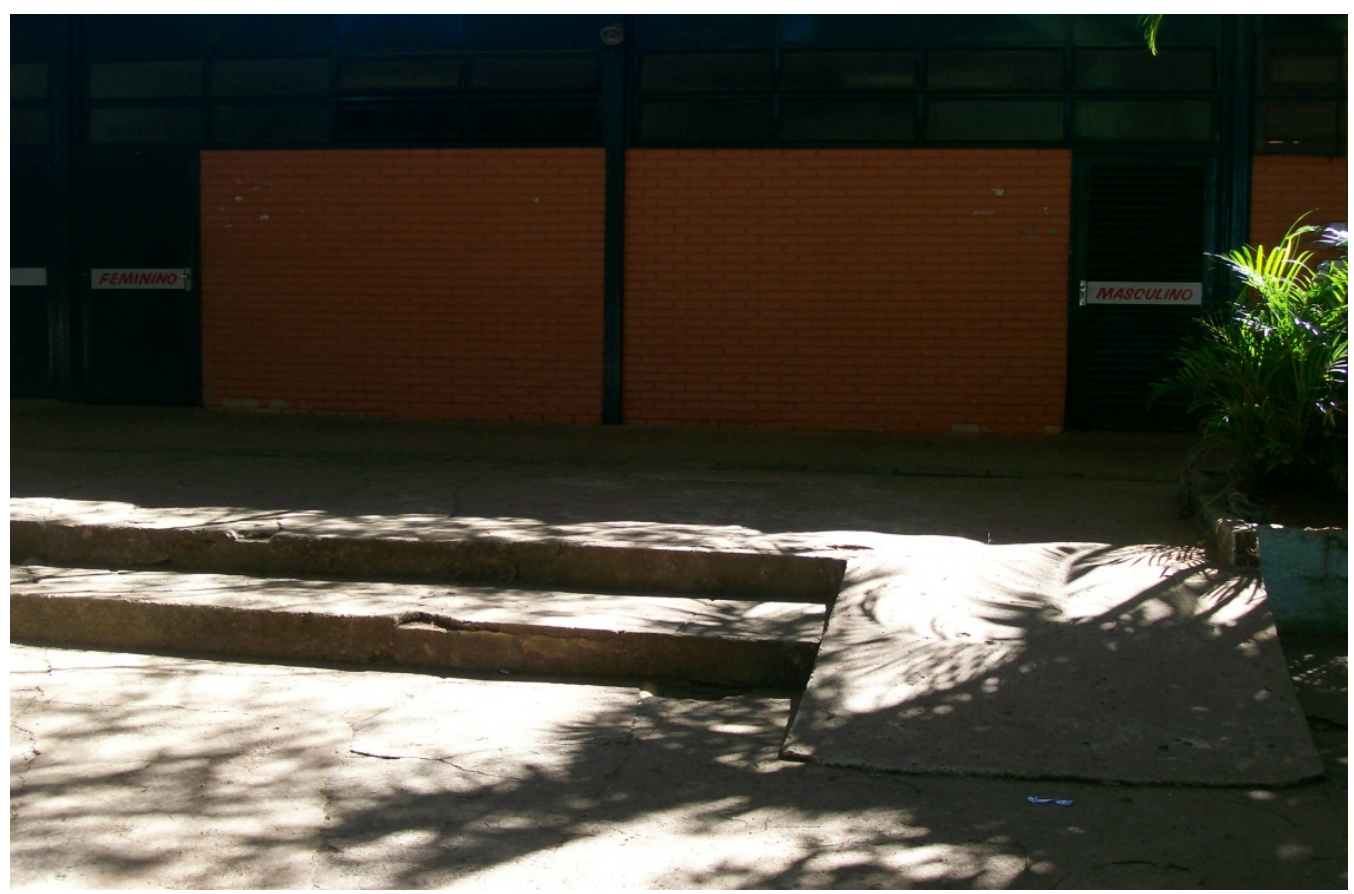

Figura 5: rampa de acesso aos banheiros, junho 2010.

Ainda existe atendimento especializado de apoio na sala de recurso para os alunos do diurno, aos alunos do noturno o apoio é feito pelo Serviço de Orientação Educacional SOE (que atua nos três turnos). 


\subsection{Conselho Escolar}

O Conselho Escolar é a entidade de natureza consultiva, deliberativa, mobilizadora e supervisora das atividades pedagógicas, administrativas e financeiras, constituída por representantes dos diferentes segmentos que integram a comunidade escolar.

Seu objetivo é cumprir com as funções determinadas na Lei, atuando de forma deliberativa, consultiva e imparcial nas decisões propostas ao Conselho Escolar em todas as Unidades de Ensino, assegurando a todos os segmentos a forma democrática de agir. Portanto, o Conselho Escolar é a instância máxima de decisão na escola.

$\mathrm{Na}$ prática, não é tão simples assim, pois, cada segmento deveria fazer as discussões necessárias, antes e depois de cada assembléia, com o objetivo de sugerir e encaminhar os assuntos de reais interesses de toda a comunidade dentro e fora da escola, e, não somente referendar o que é proposto pela direção. Apesar de ouvirmos diretores falar que o Conselho Escolar tem autonomia, na prática não é bem assim.

No entanto, o Conselho Escolar do CEM 03 de Ceilândia, tem procurado cumprir a sua função objetivando o melhor para toda a comunidade dentro e fora da escola. $\mathrm{O}$ artigo segundo do Decreto 29.207/08 estabelece que a composição do Conselho Escolar seja de um membro nato (Diretor da escola) e de, no máximo, 15 representantes eleitos dos segmentos da comunidade escolar, para mandato de dois anos.

No momento há vacâncias nos segmentos pais ou responsáveis e alunos/as. Na última reunião do Conselho Escolar, foi discutido e decidiu-se que, ao iniciar as aulas do segundo semestre de 2010, será feito a divulgação e eleição dos segmentos que estão com vacância. Os participantes são:

- Até três representantes da Carreira Magistério Público do Distrito Federal, ocupantes do cargo de Professor, em exercício na instituição educacional há pelo menos um ano;

- Um representante da Carreira Magistério Público do Distrito Federal, ocupante do cargo de Especialista de Educação, em exercício na instituição educacional há pelo menos um ano;

- $\quad$ Até dois representantes da Carreira Assistência à Educação, em exercício na instituição educacional há pelo menos um ano;

- $\quad$ Até três representantes dos discentes da instituição educacional, com idade igual ou superior a dezesseis anos, sendo, preferencialmente, um de cada turno;

Até seis representantes dos pais ou responsáveis legais de alunos da instituição educacional. 


\subsection{Direção}

Política e pedagogicamente falando, a direção atual do Centro de Ensino Médio 03 de Ceilândia está desenvolvendo um trabalho com a comunidade escolar, para garantir o bom funcionamento da escola. Como o ano de 2009 foi um período ocupado por uma direção "pró-tempore", faz-se necessário neste início de gestão a busca de uma solidez junto aos segmentos da comunidade escolar.

Aproveitando o que a escola tem de bom, a direção atual procurou manter todos os projetos já em andamento na escola, como o PROEJA - TRANSIARTE, as feiras de ciências e cultura, já tradicionais e incorporadas ao calendário da escola tanto na educação de jovens e adultos como no ensino médio matutino, entre outros.

O destaque maior deste início de gestão fica por conta da parte administrativa: melhorias no espaço físico da escola, a construção da cobertura na entrada, a reforma da cantina, pequenas reformas e a promessa da construção de um ginásio poliesportivo na área maior ao fundo, destinada à prática de Educação Física, e de um novo corredor de salas de aula.

Apesar do esforço, ajudado pela larga experiência em direções de escolas do diretor, a falta de recursos, devido geralmente a entraves administrativos é um dos principais desafios a serem superados.

O momento político atual, marcado por uma crise política no executivo e no legislativo do DF desde fins de 2009 abre uma interrogação sobre o futuro do modelo de gestão escolar a ser implementado pelo próximo governo e pela próxima legislatura a partir de 2011. Num cenário destes, somente a legitimidade dada pela comunidade escolar pode dar a força necessária para a instituição afirmar a sua identidade e o seu papel político e transformador. 


\subsection{Gestão Democrática}

Com relação ao importante aspecto, referenciado no decorrer dos módulos do curso, chamado de gestão democrática, nos seus quase 40 anos de história, o Centro de Ensino Médio 03 de Ceilândia nem sempre esteve submetido a este modelo de gestão/direção.

A gestão democrática foi um fruto da redemocratização da sociedade brasileira a partir do ano de 1985. Como o DF não elegia representantes políticos nas esferas, distrital e federal, as eleições para as direções de escolas assumiram um caráter especial junto da sociedade local, tornando-se um símbolo da expressão democrática no DF.

No entanto, somente com o Governo Democrático e Popular, a partir do ano de 2000, é que a gestão democrática encontrou condições para produzir seus melhores frutos, como a iniciação da construção de práticas multidisciplinares de trabalho pedagógico associadas à formação continuada de professores.

Fora do Governo Democrático e Popular, na esfera distrital e federal, a experiência mostra que a liberdade de tomada de decisão/ação por parte da comunidade escolar nas gestões escolares são negadas ou cooptadas, em detrimento dos interesses de grupos políticos no poder.

A representatividade e a participação da comunidade escolar é negada quando as direções são simplesmente indicadas e, cooptadas quando, de alguma forma se houve a comunidade escolar, até por meio de votação, mas se utiliza de artifícios para intervir nas gestões quando estas contrariam os interesses políticos de quem está no poder.

Recentemente, neste último governo neoliberal que está terminando seu mandato agora em 2010, foi criada a chamada gestão compartilhada, que possibilita para o governo manter o controle político legal da vontade da comunidade escolar, pois há eleições diretas para diretores de escolas, porém o governo tem o direito de aceitar ou não a qualquer tempo as direções eleitas.

No atual período de gestão compartilhada, a direção que iniciou o mandato legitimamente eleita pela comunidade escolar atendendo a todos os requisitos do processo foi afastada no início de 2009. Após um breve período de intervenção e de indicação de direção "pró-tempore" no ano de 2009, foi feito novamente o processo de escolha, no qual uma das etapas é o voto direto da comunidade escolar, onde foi eleita uma direção constituída por membros da escola. 


\subsection{O Caixa Escolar:}

O Caixa Escolar, tem a função de receber todos os recursos, que forem repassados pelo Governo Federal, Governo do Distrito Federal e pessoas físicas. É, por meio, do Caixa Escolar que são pagas as despesas da escola. Todas as movimentações feitas pelo Caixa Escolar devem ser aprovadas pelo Conselho Escolar que é a instância máxima dentro da escola que tem o poder deliberativo e consultivo. Neste momento há vacância. Os componentes são: um presidente, um vice-presidente, um $1^{\circ}$ secretário, um $2^{\circ}$ secretário, um $1^{\circ}$ tesoureiro, um $2^{\circ}$ tesoureiro, três Conselheiros Fiscais.

\subsection{Grêmio Estudantil}

O Grêmio Estudantil atua conforme Lei Distrital No 1.735, de 27 de outubro 1997, que regulamenta e dispõe sobre a livre organização dos estudantes dos ensinos fundamental e médio do Distrito Federal.

A organização dos alunos no grêmio estudantil do Centro de Ensino Médio 03 de Ceilândia pode ser definida como de caráter intermitente, uma vez que nem sempre a organização estudantil está formalmente constituída. No momento atual ela encontra-se em processo de formalização. Geralmente, os momentos em que a agremiação está formalizada e atuante, são aqueles em que, politicamente falando, a escola está com gestão democrática funcionando.

Ao iniciar o $2^{\circ}$ semestre, será aberto o processo eleitoral para que este segmento represente e participe das ações/decisões relacionados aos alunos e demais ações do coletivo da escola, como o Projeto Político Pedagógico - PPP.

\subsection{Coordenação Pedagógica}

A coordenação pedagógica no Centro de Ensino Médio 03 de Ceilândia assim como nas demais escolas da Secretaria de Educação do DF é regulamentada por portaria desta secretaria a cada início de ano letivo. Em geral os coordenadores são eleitos pelos professores, sendo a quantidade de coordenadores definida em função do número de turmas da escola.

Na Portaria $N^{0} 04$ de 21/01/2010, foi mantida a eleição pelos professores e dado 0 direito a direção de indicar um nome de coordenador. A direção da escola abriu mão da indicação, submetendo todos à eleição pelos professores.

O trabalho de coordenação é de suma importância, principalmente em escolas grandes como o Centro de Ensino Médio 03 de Ceilândia, onde a mediação do diálogo e a 
montagem dos esquemas pedagógicos que viabilizam as estratégias de ações coletivas entre alunos e professores e entre estes e os demais segmentos da comunidade escolar exigem maior trabalho de planejamento.

Além deste trabalho tido como rotineiro da coordenação pedagógica, é interessante que se tenha um envolvimento dos coordenadores articulados com direção, professores, alunos e demais segmentos da comunidade escolar no sentido de trabalhar os aspectos políticos do processo de ensino e aprendizagem, tais como as discussões a cerca do currículo escolar, da profissionalização (PROEJA - TRANSIARTE, diga-se de passagem, trabalho que está em pleno andamento e para o qual a direção designou um grupo de trabalho com professores de todas as áreas de conhecimento que se somam a outros profissionais da Escola Técnica de Ceilândia, da Faculdade de Educação - UnB, do Instituto Federal de Brasília e da SETEC - MEC, objetivando a implementação da mudança curricular com a integração do ensino profissionalizante para a Educação de Jovens e Adultos), entre outros.

Este envolvimento dos coordenadores nem sempre é possível, por vários motivos, que no caso específico do Centro de Ensino Médio 03 de Ceilândia hoje, estão relacionados à carga excessiva de trabalho.

\subsection{Orientação Educacional}

O Serviço de Orientação Educacional - SOE, passou a funcionar no CEM 03 no ano de 2000. Naquele momento havia um Orientador Educacional - OE, nos turnos, matutino/noturno, e uma Orientadora Educacional no turno vespertino permanecendo até o início do ano de 2004, quando a OE, saiu da escola, permanecendo somente um.

No segundo semestre de 2009, passou a ter mais um OE, nos turnos: matutino e vespertino. Com a saída do OE, que havia chegado no segundo semestre de 2009, abriu-se carência na modulação da escola e, então no início do ano letivo de 2010, chegou ao CEM 03, uma OE, para trabalhar nos turnos matutino e vespertino, muito importante naquele momento esta conquista, respeitando assim, a questão de gênero.

Diante da demanda da escola, há necessidade de mais OE. O SOE, tem como objetivo propiciar o desenvolvimento histórico social/global dos alunos, procurando trabalhar as suas potencialidade e dificuldades, no individual ou coletivo, e também com todos os segmentos dentro e fora da escola (alunos, escola e comunidade).

Por isso a participação do Orientador Educacional - OE, é de suma importância desde a construção do Projeto Político Pedagógico - PPP até a sua execução. Contribuindo assim, para a formação de um cidadão crítico-participativo, além de promover a integração entre todos os segmentos da escola, como também fortalecendo o elo entre 
família/escola/aluno, participando do Conselho Escolar, das coordenações coletivas, conselhos de classe, ou seja, participando/intervindo em todas as ações da escola.

3.8. Programa Especializado para Alunos com Necessidades Educacionais Especiais ANEEs - Sala de Recurso

O Programa de atendimento especializado de apoio aos ANEEs, é realizado na Sala de Recurso no diurno, aos alunos do noturno o apoio e acompanhamento é feito pelo Serviço de Orientação Educacional - SOE (que atua nos três turnos), oferecendo orientação e acompanhamento a todos os alunos, famílias e professores sempre que solicitado ou, através de uma analise prévia junto à comunidade escolar, onde necessita a intervenção do SOE.

Dentre o público-alvo do PROEJA - Transiarte, temos alunos Portadores de Necessidades Especiais - ANEEs, sendo assim, o CEM-03, trabalha numa perspectiva de Educação Inclusiva. A LDB, em seu Art. 58, estabelece que a Educação Especial seja preferencialmente oferecida na rede regular de ensino, visando à integração da criança e do jovem com necessidades educacionais especiais com os demais alunos do ensino regular.

Ainda na Educação Inclusiva, é importante registrar em nossa escola a BANDA TOQUE ESPECIAL, (jovens e adultos com Deficiência Intelectual e Deficiências Múltiplas), que se apresenta em outras Unidades da Federação, além do Distrito Federal (veja a figura $6)$. 


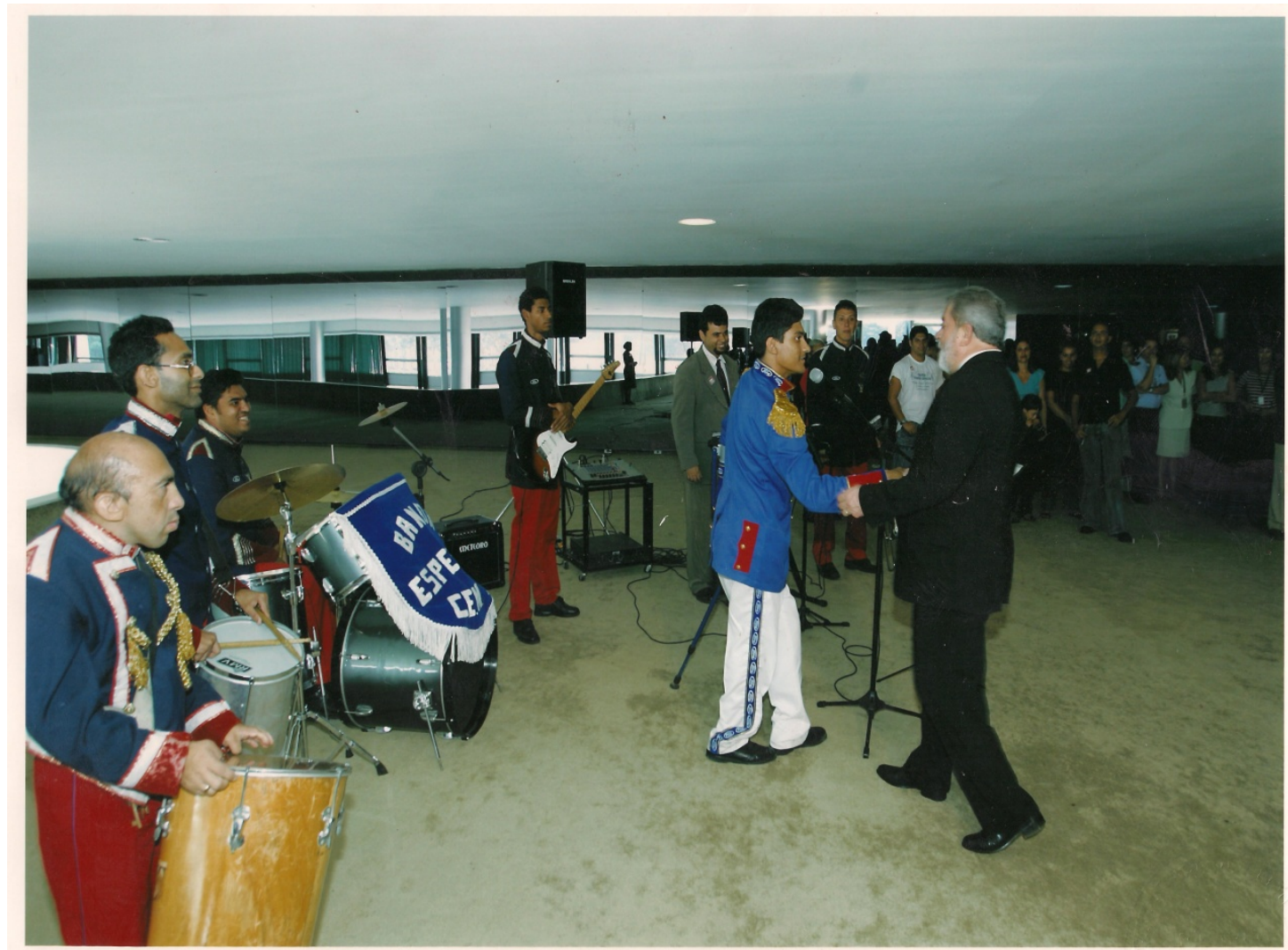

Figura 6: Apresentação no aniversário do Presidente Luiz Inácio Lula da Silva, no Palácio da Alvorada, outubro de 2005.

\subsection{O Projeto Político e Pedagógico}

O Projeto Político Pedagógico - PPP, conforme art. 55, Regimento Escolar das Instituições Educacionais da Rede Pública de Ensino do DF, deve ser elaborado anualmente, observadas as normas legais vigentes, o Plano Nacional de Educação, a Resolução do Conselho de Educação do Distrito Federal, o Plano de Educação do Distrito Federal, as Diretrizes Pedagógicas e as Orientações Curriculares da Secretaria de Estado de Educação, assumindo o caráter orientador da prática educativa.

O Projeto Político Pedagógico (PPP) do Centro de Ensino Médio 03 de Ceilândia começou a ser construído coletivamente com a sua comunidade escolar a partir do ano de 2008, por meio de chamadas públicas para construção, discussão e implantação das ações propostas. Como a sociedade e a comunidade escolar são partes de um processo social e político dinâmico ou em constante evolução/transformação, ele nunca pode ser dito pronto e acabado, mas em constante processo de desenvolvimento ou aperfeiçoamento visando sempre o melhor para a comunidade escolar e local. 
A construção/reconstrução do Projeto Político Pedagógico - PPP dá-se a partir da construção coletiva, devendo envolver todos os segmentos da escola. Neste ano de 2010, foi reconstruída a nova proposta pedagógica para o Centro de Ensino Médio 03, no entanto, percebe-se que depois de pronto o PPP, faltam ainda mencionar alguns projetos, como o PROEJA - TRANSIARTE (desde 2007) e o Saúde e Prevenção (desde 2000). Como a escola está passando por um momento de reconstrução, presume-se que na pressa de apresentar para Diretoria Regional de Ensino de Ceilândia, não foram feitas as discussões necessárias, a partir das coordenações gerais e depois aprofundadas nas coordenações por áreas de conhecimento. No entanto, não se constrói uma história desconhecendo o passado e será necessário corrigir o PPP na próxima revisão.

Desta forma, linhas gerais são mantidas e eventuais ajustes devem ser discutidos com a comunidade escolar conforme o processo de desenvolvimento social, político, econômico, cultural, histórico e educacional se desenvolve. No Portal dos Fóruns de EJA DF (link) encontram-se as duas versões do PPP, a primeira implantada em 2008 e a segunda, já com algumas modificações, de 2010. 


\subsection{Movimento Sindical, Político e Classista}

O papel do Centro de Ensino Médio 03 de Ceilândia no movimento sindical dos professores e demais trabalhadores em educação do Distrito Federal foi e é de grande importância. Em tempos de ditadura militar e de redemocratização, a cidade de Ceilândia destacou-se como uma referência para o movimento sindical dos professores no DF e o Centro de Ensino Médio 03 de Ceilândia foi uma referência deste movimento na cidade. No Centro de Ensino Médio 03 de Ceilândia já trabalharam professores que foram ou tornaramse dirigentes do Sindicato dos Professores no Distrito Federal - SINPRO - DF, depois se tornaram políticos no cenário do Distrito Federal.

Após as eleições diretas para Presidente da República em 1989 e a consolidação da democracia no país até a atualidade, o Centro de Ensino Médio 03 de Ceilândia continuou sendo um reduto importante para o movimento sindical dos professores seja pelo fato de lá terem trabalhado dirigentes do SINPRO - DF, políticos do cenário distrital e partidário, dirigentes da Associação de Assistência aos Servidores da Fundação Educacional do Distrito Federal - ASEFE, um ex-administrador da Região Administrativa de Ceilândia (RA IX), seja pelo fato da escola ser um reduto social importante para a comunidade ceilandense (pela importância do seu auditório, bastante requisitado, da sua área destinada à prática esportiva e pelos eventos lá realizados).

\subsection{Trabalhadores Terceirizados}

Já faz quase uma década que os trabalhadores terceirizados chegaram ao Centro de Ensino Médio 03 de Ceilândia para substituir os funcionários do quadro permanente de pessoal da Secretaria de Educação do Distrito Federal. Estes últimos eram efetivamente parte da comunidade escolar, tinham laços profissionais com a escola e, também laços sociopolíticos. Chegavam mesmo a assumir a função de educadores no trato com os alunos e a comunidade escolar.

O modelo neoliberal e privatista que se tornou mais arraigado a partir da década de 1990, ajudou a tornar insatisfatório o resultado do trabalho destes profissionais, uma vez que dificilmente havia renovação através de novos concursos públicos, logo o quadro de pessoal envelhece, tem problemas de saúde, queda de produtividade, se aposenta e os que ficam na ativa não dão conta de manter a eficiência do serviço prestado.

Como resposta para resolver o problema da falta de mão de obra para o trabalho dos serviços gerais (limpeza e arrumação), o modelo neoliberal apresenta a terceirização como solução, sem que seja feita uma discussão no âmbito da comunidade escolar para se avaliar 
quais os reais custos deste tipo de atividade, suas conseqüências para a classe trabalhadora e para o próprio processo de ensino e aprendizagem e seus desdobramentos sociais, políticos e educacionais.

Os trabalhadores terceirizados estão sujeitos a uma rotatividade em seus locais de trabalho que não existia da mesma forma com os do quadro permanente da Secretaria de Educação, logo não criam laços duradouros com o ambiente em que trabalham, são funcionários de uma empresa e não da escola. Também não se fazem representar no Conselho Escolar e não integram, a não ser de forma ocasional e sem representação ou força política, a comunidade escolar.

Pela importância da educação pública para a sociedade, melhor seria investir em boas condições de trabalho e realização de concursos públicos para contratação de pessoal capacitado para o trabalho nas escolas, tendo em vista inclusive a implicação destes profissionais como educadores no processo de ensino e aprendizagem (imagine que um porteiro(a) ou um(a) auxiliar de limpeza é capaz de conversar com um ou mais alunos e mostrar autoridade moral, pelos laços profissionais, históricos e afetivos que mantêm com a escola, para orientá-los quanto ao porquê de não saírem, tentarem fugir ou mesmo perambular pelos corredores da escola em seu horário de aula ou naquele horário em que vão fazer um trabalho em grupo ou de pesquisa na biblioteca ou dependências da escola. Da mesma forma, um(a) merendeiro(a) é capaz de orientar um aluno sobre o porquê não deve comer tal ou qual alimento em excesso ou porque a dieta do lanche da escola é feita de tal ou qual cardápio, assim como pode interagir com as atividades multidisciplinares em uma feira cultural ou de ciências).

Um último aspecto dos trabalhadores terceirizados que merece destaque é o dos vigias. Conforme dito anteriormente, estes trabalhadores terceirizados são funcionários de uma empresa e não da escola, logo não possuem laços sólidos com a comunidade escolar pelos mesmos motivos também citados anteriormente.

A segurança é uma obrigação do poder público e depende de uma política pública específica, está ligada a bons indicadores socioeconômicos e políticos, a uma educação de qualidade, tanto em seu aspecto propedêutico quanto profissional, a uma saúde de qualidade e a uma melhor distribuição de renda. Esta política pública deve ser articulada com as outras políticas de desenvolvimento social envolvendo um trabalho coletivo com benefício para todo o conjunto da sociedade. Além de tudo isso é necessário que todo este trabalho seja feito visando uma construção de bons valores morais e filosóficos. Com uma boa aparelhagem e com uma boa estrutura de recursos humanos os vigias da própria Secretaria de Educação do DF também podem fazer um trabalho de qualidade. 


\section{Justificativa e Caracterização do Problema}

A experiência do Prof. Dr. Renato Hilário dos Reis, no período de 1970 até 1973, como diretor do Colégio Municipal Inconfidentes de Contagem - MG e, atualmente trabalhando na Faculdade de Educação - FE - UnB, mais a minha experiência profissional como professor e educador no CEM 03 despertou o meu interesse para a importância da família do estudante de EJA para a formação de uma ação coletiva cidadã capaz de reconhecer, intervir e transformar para melhor a sociedade em que vive começando pela sua comunidade escolar e pela sua comunidade local.

O jovem, o adulto e o idoso trabalhador são vítimas da opressão social, política e econômica que a sociedade brasileira lhes impôs ao longo de cinco séculos de história de exploração do trabalho, primeiramente através da escravidão e depois através do trabalho remunerado e assalariado de baixa qualificação.

Diferentemente do ensino regular tradicional, a EJA tem seu público característico formado por jovens adultos e idosos que estão em defasagem na idade-série devido a vários motivos, mas principalmente pela necessidade precoce de precisar trabalhar e cuidar da família.

Com a redemocratização da sociedade brasileira a partir da década de 1980, a participação política das classes sociais ganhou importância nas decisões e rumos do desenvolvimento econômico e político do país. A qualificação profissional e o ensino propedêutico assumiram ao longo deste tempo e, particularmente, após a virada do século XXI condição indispensável para o trabalho e, principalmente, para o trabalho qualificado.

Estudar passou a ser uma necessidade exigida pelo mercado de trabalho, se qualificar uma necessidade para melhoria das condições de trabalho e salariais. Seguir os estudos no nível superior passou a ser uma possibilidade de melhoria nas condições de vida. As oportunidades e boas condições para tanto, contudo, não foram criadas. Para voltar a estudar e seguir os estudos é necessário condições adequadas que levem em conta as necessidades específicas do público jovem, adulto, idoso e trabalhador. Um currículo adequado, com metodologias de ensino adequadas, uma estrutura física, de recursos humanos, materiais e de transporte público, entre outros, que sejam voltados às necessidades do público da EJA.

Para o estudante de EJA se libertar da realidade opressora, a si mesmo e ao próprio opressor $^{1}$, é necessário a atuação coletiva trabalhando com seu grupo social buscando uma

\footnotetext{
${ }^{1}$ Sobre a relação opressor-oprimido, leia o prefácio do livro Pedagogia do Oprimido, primeiro parágrafo na página 5, escrito pelo Professor Ernani Maria Fiori e, no próprio texto do autor, o primeiro parágrafo do subtítulo
} 
intervenção na sociedade que produza transformações nas relações sociais e coletivas que tenham como conseqüência a mudança. Este trabalho coletivo buscando transformação e mudança na sociedade pode ser feito, tanto nas associações comunitárias e nos movimentos sociais quanto na escola pública, juntamente com a comunidade escolar e com a gestão democrática participativa na instituição.

A escola é um espaço de convivência social que pode se articular social e politicamente com a sociedade em nível local. Por meio de seus eventos pedagógicos e da construção coletiva de uma gestão democrática participativa e de seu Projeto Político Pedagógico (PPP), a comunidade escolar é responsável pela criação das estratégias de desenvolvimento das ações políticas e pedagógicas que constroem a identidade da escola e o seu processo de ensino e aprendizagem conforme definido em seu PPP

A comunidade escolar não é restrita a convivência intra-muros da instituição escola, mas vai além, estando presente na sociedade do lado de fora, ela própria é uma comunidade que faz parte deste todo que é a sociedade funcionando em sua dimensão local.

A falta de uma ação coletiva cidadã dos alunos de EJA, em função da estrutura produtiva e social excludente que oprime o educando trabalhador e sua família, Ihe tira o acesso a uma educação/formação profissional (emancipadora e criadora) de qualidade que o ajude a vencer a pobreza e a falta de acesso a produção cultural, resultante do trabalho social coletivo.

É condição essencial, para superar este problema, que se tenha uma gestão democrática na escola, onde a comunidade atue no processo de mudança da realidade local, por meio de sua ação política, se mobilizando e cobrando das autoridades instituídas pelo poder público, também de forma democrática, ações que acabem com as injustiças sociais.

Tal mobilização deve ser feita pelo trabalho sociopolítico e pedagógico, referendado pela comunidade escolar e tendo à frente esta mesma comunidade para conduzir tal processo por meio de suas lideranças e representações políticas legitimamente eleitas e empossadas (o conselho escolar, a direção, a coordenação pedagógica e todas as que eventual ou permanentemente forem criadas com a função de construir as relações da comunidade escolar com a sociedade em seu nível loca).

A família torna-se peça fundamental neste jogo político, pois é a célula básica de organização da sociedade, onde todas as decisões/ações políticas devem legitimamente ser problematizadas, para terem efetivo poder de modificar a realidade opressora. O potencial

"A CONTRADIÇÃO OPRESSORES-OPRIMIDOS. SUA SUPERAÇÃO", nas páginas 16-17. FREIRE, Paulo. Pedagogia do Oprimido. Paz e terra. 1970. 
de entendimento e de organização da família para alcançar com êxito os objetivos construídos coletivamente são mais eficientes do que os de qualquer outro grupo social.

Através das representações sociais e políticas da comunidade escolar, toda a família deve ser chamada a participar e construir as ações sociopolíticas e pedagógicas da escola, visando à transformação da realidade opressora e excludente que limita o acesso ao produto do trabalho na perspectiva da produção social da nossa forma de vida ou da nossa cultura.

A família para o estudante de EJA é vista de forma diferente daquela do estudante do ensino regular tradicional. O estudante de EJA é, em geral, um chefe de família ou, no caso dos idosos, alguém que já criou seus filhos e, portanto, não depende dela para responder por si, no entanto, a importância da família do estudante de EJA não é secundária, tem um papel importante na formação da ação coletiva cidadã, quando não é o motivo mais importante da razão de ser da presença do estudante na escola, uma vez que ele busca melhores condições socioeconômicas de vida para si e sua família, dando continuidade aos seus estudos, muitas vezes devido às exigências do mercado de trabalho que requer mais formação e certificação educacional e profissional.

Mobilizar a família do estudante de EJA para garantir qualidade, a continuidade, a conclusão dos seus estudos e a sua ação coletiva cidadã não quer dizer trazê-la permanentemente para dentro da escola e nem conseguir trazer todas as famílias de todos os alunos para a participação efetiva do dia-a-dia escolar, mas sim mantê-la ciente do papel democrático-participativo da escola e do seu potencial de chamar a atenção para as necessidades da comunidade local (bairro e Região Administrativa) enquanto um espaço de reunião, tanto da comunidade escolar, quanto desta com os movimentos sociais que lutam por melhores condições de vida na sociedade.

Este papel democrático-participativo da escola e o seu potencial de chamar a atenção para as necessidades da comunidade local, tanto em nível reivindicatório, como no de influência das decisões relativas às ações políticas a serem tomadas, como no de participar coletivamente da realização destas ações que deverão serem implementadas para melhorar a realidade local é uma forma de problematizar a conjuntura social, política, econômica e cultural da sociedade atual e fazer as pessoas serem levadas a entenderem e intervirem criticamente nesta sociedade, que é tão somente a sociedade composta por todos nós, onde cada um a constrói coletivamente a partir do seu trabalho ou da sua ação na dimensão local.

Desta forma, atividades como o Projeto Cine Popular, do CEPAFRE (Centro de Educação Paulo Freire de Ceilândia), que chama toda a comunidade local para um diálogo em torno de um tema e suas variantes, abordados a partir do visionamento de um filme, quase sempre nos finais de semana, quando é mais viável a presença das famílias da 
comunidade local na escola, é um precioso momento de conscientização e análise de conjuntura do processo político, social, econômico e cultural da sociedade e, também, um momento de se conscientizar da responsabilidade de cada um enquanto membro de um grupo social com poder interventor, criador e transformador da realidade na qual vivemos. Acessando o Portal dos Fóruns de EJA/DF no link http://forumeja.org.br/df/cinepop, pode-se conhecer melhor o Projeto Cine Popular e o CEPAFRE.

Igualmente um espaço e um momento conseguidos na escola por um movimento social de uma dada variante das modalidades de yoga, (como,por exemplo, a Sahaja Yoga) que convide alunos e suas famílias para uma prática de meditação e melhoria das condições pessoais e, por conseguinte, das relações coletivas do indivíduo na sociedade, também tem como finalidade criar melhores condições de vida que transformem as relações sociais e coletivas. Para conhecer melhor a Sahaja Yoga acesse 0 site http://www.sahajayoga.org.br/.

Da mesma forma as atividades do Grupo Rio Abierto, que também pode ser conhecido no Portal dos Fóruns de EJA/DF nos links http://www.forumeja.org.br/df/rioabierto e http://www.rioabierto.org.arl, é outro exemplo de ação possível de se fazer junto a comunidade local com o objetivo de criar uma ação coletiva cidadã entre as pessoas transformando para melhor a qualidade de vida das mesmas e as suas relações sociais e coletivas.

Também, um grupo que desenvolve algum tipo de atividade física com as pessoas da comunidade local procurando criar hábitos de vida saudáveis, para o bem estar coletivo, é outro exemplo de ação com a finalidade de melhorar as relações sociais e coletivas e de criar condições que possibilitem a mobilização e organização visando a participação nas decisões/ações políticas da vida local (intervindo, criando e transformando a realidade).

Uma iniciativa que ofereça a oportunidade de iniciação às artes marciais como prática de uma atividade física e mental saudável, buscando equilíbrio emocional e mental e criando uma cultura de paz e respeito pelos valores individuais e coletivos e ajudando a desenvolver as boas potencialidades do indivíduo é exemplo de ação que pode transformar para melhor a vida da comunidade local.

Concretamente o Projeto PROEJA - Transiarte, que está sendo aplicado na escola desde o ano de 2007 e que se utiliza da metodologia da Pesquisa-Ação ${ }^{2}$ com o objetivo de intervir na realidade local se utilizando de ferramentas de tecnologias virtuais, ajudando na formação e qualificação de sujeitos críticos e participativos diante da realidade social é outra iniciativa de trabalho coletivo que objetiva a melhoria das relações sociais entre os indivíduos e, consequentemente, a prática de uma ação coletiva cidadã. Para conhecer o

\footnotetext{
2 Para conhecer a Pesquisa-Ação, leia o livro de René Barbier intitulado "A Pesquisa-Ação".
} 
PROEJA - Transiarte, visite o Portal dos Fóruns de EJA - DF no link http://forumeja.org.br/df/?q=transiarte.

\section{Objetivos}

\subsection{Objetivo Geral}

Buscar a participação da família do estudante de Educação de Jovens e Adultos nos eventos pedagógicos da escola e nos eventos conjuntos com os movimentos sociais e da sociedade civil organizada com o objetivo de levantar os principais problemas da comunidade local e problematizá-los fazendo uma análise de conjuntura social, política, econômica e cultural para buscar as soluções e melhorias em nível reivindicatório, de influência decisória nas ações a serem adotadas e de participação coletiva na realização destas ações, visando uma intervenção na sociedade local que produza melhoria nas relações sociais, coletivas e na qualidade de vida das pessoas, definindo assim uma ação coletiva cidadã.

\subsection{Objetivos Específicos}

I. Apresentar este PIL ao Conselho Escolar do CEM 03, representação onde alunos e suas famílias, integrantes da comunidade local, possuem representação e participação legal, objetivando conseguir a legalidade e legitimidade para a sua aplicação junto da comunidade escolar do Centro de Ensino Médio 03 de Ceilândia - DF. Nesta ocasião convidar o Prof. Dr. Renato Hilário para dar seu depoimento sobre a sua experiência como diretor do Colégio Municipal Inconfidentes, em Contagem - MG e a Prof ${ }^{a}$ Dra. Maria Luiza Pereira Angelim para fazer as suas considerações como Orientadora deste PIL.

II. Formar juntamente com as representações sociais e políticas presentes na comunidade escolar (conselho escolar, direção coordenação pedagógica e todas as que eventual ou permanentemente forem criadas com a função de construir as relações da comunidade escolar com a sociedade em seu nível local) um grupo de trabalho para problematizar, por meio dos eventos pedagógicos do calendário escolar e dos eventos conjuntos com os movimentos sociais e da sociedade civil organizada, as decisões/ações políticas da comunidade local com as famílias dos estudantes de EJA.

III. Revisar, semestralmente pelo grupo de trabalho citado no item II, o Projeto Político Pedagógico da escola a fim de mantê-lo atualizado com a conjuntura social, política, econômica e cultural da comunidade local e com as políticas públicas para a Educação de 
Jovens e Adultos - EJA. Os períodos de revisão do PPP podem ser redefinidos conforme decisão do grupo de trabalho citado.

IV. Planejar, com o grupo de trabalho citado no item II, a inserção nos eventos pedagógicos do calendário escolar a abertura para a participação das famílias dos alunos de EJA, da comunidade local e dos movimentos sociais e da sociedade civil organizada nestes eventos.

V. Definir o número de alunos de Educação de Jovens e Adultos - EJA para dar início ao PIL no segundo semestre letivo de2010, conforme critério a ser elaborado coletivamente pelo grupo de trabalho citado no item II.

VI. Convidar os movimentos sociais, a sociedade civil organizada e a família dos estudantes de EJA para participarem dos eventos pedagógicos do calendário escolar e a criarem uma rotina de participação no ambiente escolar com atividades que integrem a comunidade escolar com a problematização acerca das decisões/ações políticas da comunidade local. Exemplos de movimento sociais e da sociedade civil organizada são: o CEPAFRE (Centro de Educação Paulo Freire de Ceilândia, que desenvolve atividades como o Cine Popular e a alfabetização de adultos na cidade), as Associações Comunitárias de Moradores, grupos folclóricos, grupos de dança, igrejas, grupos que desenvolvem atividades físicas de integração e recreação entre os membros da comunidade local visando uma melhoria na qualidade de vida individual e coletiva das pessoas, mídia, entre outros. Para este item usar, em atividade a ser planejada pelo grupo citado no item II, um debate com o Prof. Dr. Renato Hilário (um dos motivadores deste PIL; leia a seção 4), a Prof $^{a}$ Dra. Maria Luiza Pereira Angelim (Orientadora deste PIL), a Dra. Catarina Almeida Santos (avaliadora deste PIL) e toda a equipe do Projeto PROEJA - Transiarte, que atuam na escola desde o ano de 2007 (leia a seção 4), utilizando o vídeo "Tribus", disponível no link http://www.proejatransiartetube.cefetgo.br/, que fala do encontro de gerações, como um motivador do início dos trabalhos. 


\section{Atividades/Responsabilidades}

O PIL será realizado por meio da sua apresentação ao Conselho Escolar da escola, para conhecimento e legitimação do trabalho e da formação do grupo de trabalho citado no item II dos objetivos específicos que estabelecerá ao início de cada semestre letivo suas estratégias de ações para então montar o planejamento dos eventos do calendário pedagógico da escola, procurando inserir espaços de participação para as famílias dos estudantes de EJA, a comunidade local e os movimentos sociais e da sociedade civil organizada nas atividades a serem desenvolvidas durante cada semestre letivo, começando pelo segundo semestre de 2010.

Deverá ser planejado pelo grupo de trabalho definido no item II dos objetivos específicos as revisões semestrais do PPP da escola. Estas revisões devem ser feitas anualmente, porém nem sempre assim ocorre. As revisões semestrais são uma suugestão pensando no calendário da EJA que é semestral.

O grupo de trabalho definido no item II dos objetivos específicos também deverá planejar o início das atividades do PIL com a comunidade escolar e local organizando e colocando em prática os itens IV, V e VI dos objetivos específicos.

É importante lembrar que nem todas as famílias de alunos de EJA ou mesmo todos os membros da comunidade escolar participam plenamente das atividades pedagógicas da escola. A adesão às atividades varia em função de fatores como, principalmente a avaliação e o envolvimento dos professores nas atividades desenvolvidas.

O sucesso do trabalho de coordenação pedagógica, integrado as estratégias de ações pedagógicas da direção é que dão o rumo da eficácia ou não das atividades desenvolvidas em cada semestre letivo. Convém, conforme estabelecido no item IV dos objetivos específicos, definir o número de estudantes com que se deseja trabalhar e obter algum resultado, partindo sempre de algo simples (menor número) para depois se atingir algo mais complexo (maior número).

Assim sendo pode-se começar o PIL com o número de alunos a ser definido conforme o item IV dos objetivos específicos e, progressivamente, construir coletivamente na rotina de trabalho, a ampliação deste universo até que se possa atingir a totalidade dos alunos de EJA da escola. É natural que em dados momentos haja uma grande sensibilização para uma dada atividade, em outros a mobilização e o interesse sejam mais fracos e que, com o tempo, o trabalho produza frutos que the dê credibilidade e adesão perante o público ao qual se destina. 


\section{Cronograma}

A realização deste PIL deverá seguir um cronograma definido pelo grupo de trabalho descrito no item I dos objetivos específicos, que planejará suas estratégias de trabalho e ação sempre ao início de cada semestre letivo no Centro de Ensino Médio 03 de Ceilândia DF.

Ao final de cada semestre letivo deverá ser feita uma avaliação coletiva do trabalho desenvolvido pelo próprio grupo de trabalho anteriormente e pelos demais participantes envolvidos no trabalho.

\section{Parceiros}

Os parceiros deste PIL são as representações sociais e políticas instituídas legal e legitimamente na comunidade escolar, Conselho Escolar, Direção Coordenação Pedagógica e todas as que eventual ou permanentemente forem criadas com a função de construir as relações da comunidade escolar com a sociedade em seu nível local, o serviço de Orientação Educacional, a Secretaria da Escola, os professores e os movimentos sociais e da sociedade civil organizada que venham a se envolver no projeto.

\section{Orçamento}

Os gastos com a implementação deste PIL só podem ser estimados a partir do planejamento das estratégias de trabalho ao início de cada semestre letivo pelo grupo de trabalho definido no item I dos objetivos específicos, levando-se em conta, a partir do segundo semestre de sua aplicação, a avaliação das atividades e as experiências de trabalho acumuladas no semestre anterior. 


\section{Acompanhamento e Avaliação}

O acompanhamento e a avaliação deste PIL deverão ser feitos a cada semestre letivo pelo grupo de trabalho definido no item I dos objetivos específicos e por meio dos demais parceiros envolvidos na realização de suas atividades e estratégias de ação.

Deve ser feita, ao final de cada semestre letivo, uma avaliação coletiva do trabalho desenvolvido. Esta avaliação deve ser feita pelo grupo de trabalho anteriormente citado, que deve se auto-avaliar e ouvir a avaliação dos participantes envolvidos no trabalho. Eventuais modelos de fichas ou formulários de avaliação a serem utilizados devem ser elaborados coletivamente pelo mesmo grupo de trabalho referido e pelos demais participantes envolvidos no trabalho.

\section{Referências Bibliográficas}

BARBIER, René. A Pesquisa-Ação. Tradução de Lucie Didio. Brasília: Líber Livro Editora, 2007.

FREIRE, Paulo. Pedagogia do Oprimido. Paz e Terra. 1970

PROPOSTA político pedagógica do centro de ensino médio 03 de Ceilândia - DF do ano de2008. Ceilândia - DF, 2008.

PROJETO proeja - transiarte. Disponível em: http://forumeja.org.br/df/?q=transiarte. Acesso em: 01/07/2010.

SOCIEDADE Sahaja Yoga do Brasil. Disponível em: http://www.sahajayoga.org.brl. Acesso em 23/07/2010.

FUNDACION Río Abierto. Disponível em: http://www.rioabierto.org.ar/. Acesso em 23/07/2010.

. Disponível em: http://www.forumeja.org.br/df/rioabierto. acesso em 23/07/2010.

PROJETO cine popular. Disponível em http://forumeja.org.br/df/cinepop. Acesso em $15 / 06 / 2010$

http://maps.google.com/maps?|l=-15.820116,-48.096478\&z=15\&t=h\&hl=pt-BR. Acesso em: 01/06/2010.

http://www.forumeja.org.br/df/cidades. Acesso em: 24/06/2010

LEI de diretrizes e bases da educação nacional - LDB - Lei 9394/96. Brasília: Câmara dos Deputados, 1997

PROPOSTA político pedagógica do centro de ensino médio 03 de Ceilândia - DF do ano de 2010. Ceilândia - DF, 2010. 
VÍDEO tribus. Disponível em: http://www.proejatransiartetube.cefetgo.br/. Acesso em: 01/07/2010. 